\title{
Juvenile Brides: Domestic Violence in Pregnancy
}

\author{
Gulbeyaz Baran, ${ }^{1, *}$ and Funda Gumus ${ }^{1}$ \\ ${ }^{1}$ School of Nursing, University of Dicle, Diyarbakir, Turkey \\ "Corresponding author: Gulbeyaz Baran, School of Nursing, University of Dicle, 21100/Diyarbakir, Turkey. Tel: +90-4122488001, E-mail: rozbaran@gmail.com
}

Received 2017 March 20; Revised 2017 June 13; Accepted 2017 July 19.

\begin{abstract}
Background: Juvenile marriage is a violation of human rights. Previous studies state that female children are both subjected to more problems compared to male children and are at more risk in terms of mortality and morbidity. Violence towards woman is a universal problem that is common in every culture and society in the world. It has been reported that domestic violence is higher in juvenile marriages and that it continues during pregnancy. However, there was no study in the literature that researched domestic violence towards married juveniles who are pregnant.

Objectives: To assess situation regarding domestic violence towards married pregnant juveniles.

Methods: This research was conducted a sectional, descriptive study. The population of the research was formed of females who were pregnant, between the ages of 10 and 19 between January and July 2016, and had married as juveniles. The population of the research consisted of pregnant girls who were between the ages of 10 and 19 between January and July 2016 and who had entered into a juvenile marriage. We planned to reach the entire population without sampling in this study. The research was formed of 79 pregnant juvenile brides in total; $(n=54)$ registered in twenty family health centers (ASM's) in the Yenisehir, Kayapinar, Baglar and Sur provinces of Diyarbakir and $(\mathrm{n}=25)$ of them were not registered. percentages, averages, the Fisher exact test and Pearson chi-square tests were used in the analysis of the data.

Results: The average age of the pregnant married girls/adolescents who were included within the research was $17.86 \pm 1.00$. It was found that $26.0 \%$ of the pregnant juveniles had been subjected to violence during their pregnancy. They stated that they were subjected, respectively, to verbal (51.9\%), physical (26.6\%), emotional (27.8\%), sexual (11.4\%) and economic (11.4\%) violence. It was established that exposure to violence was affected by whether the marriage was involuntary or voluntary $(\mathrm{P}=0.011)$ and whether they perceived their relationship status to be $\operatorname{good}$ or bad $(\mathrm{P}=0.00)$.

Conclusions: Nurses, who encounter individuals face-to-face more than other workers because of the very nature of their roles, have a significant responsibility in this regard.
\end{abstract}

Keywords: Pregnancy, Child Violence, Abuse

\section{Background}

Juvenile marriage is the marriage that occurs generally before the age of 18 and without the juvenile being ready for the responsibility of marriage and bearing a child, whether physically or psychologically(1). It is reported that over 700 million women around the world were married before they turned 18 and over 250 million women before they turned 15 (2). While the distribution of juvenile marriages around the world varies, it is most common in south Asia, northern Africa, the Middle East, Latin America and West Africa. Considering the size of population, roughly half of child/adolescent brides are found in the south Asian region, primarily in Afghanistan, Ethiopia, Bangladesh, India and Nepal (3). According to results of a study that was conducted in 47 countries across the world, the age at which the first marriage occurs is gradually increasing, despite the fact that this situation is restricted to daughters of families of high income. In accordance with the estimates and considering the decline in early marriages in the last 30 years, it is assumed that the number of early marriages will fall to 570 million as of 2030 and 450 million as of 2050 (2).

Early marriages are generally influenced by factors such as poverty, cultural traditions, sexual discrimination and the educational level (2). When these marriages are analyzed, it is determined that families are motivated towards early marriage because they believe that they and their children will become richer and that their children will be better clothed and nourished (4).

Juvenile marriage is a violation of human rights (5). Previous studies state that female children are both subjected to more problems compared to male children (2) and are at more risk in terms of mortality and morbidity. 
For a child who is not yet fully developed, early marriage results especially in frequent unplanned pregnancies, sexually transmitted diseases such as $\operatorname{HIV}$ /AIDS $(6,7)$, a reduced level of success at school, serious exposure to abuse and violence from the spouse and others (2), social isolation and suicide (8) and as punishment, being murdered in what is called 'honor killing'.

Annually, 16 million girls between ages of 15 and 19 give birth worldwide, and this rate corresponds to $11 \%$ of the births around the world. In countries with a low and medium level of income, almost $10 \%$ of girls become mothers before the age of 16 . This rate is highest in the subSaharan region of Africa and the southeast and centralsouth regions of Asia. The proportion of juveniles who become pregnant before the age of 15 differs considerably even in the sub-Saharan area of Africa. For instance, while the rate in Mozambique is $12.2 \%$, the rate in Rwanda is $0.3 \%$ (9). In the research that was conducted about domestic violence towards adult pregnant women, it was stated that their exposure to domestic violence varied from1 to $32 \%$ (9).

There is only a limited number of studies determining the situation regarding juvenile marriage in Turkey. The facts that these marriages fall under the category of "unofficial marriage" and that juvenile brides cannot utilize healthcare services during their pregnancies make it impossible to determine the exact number (4). However, the Turkish population and health research (10) results show that the proportion of juvenile marriages in the 15 to 19 year-old age group is $7.1 \%$ and the maternity rate of married girls is 5\% (10). It has been stated that domestic violence towards pregnant women in Turkey occurs in between 20 and $74 \%$ of pregnancies $(11,12)$. In a survey of the literature regarding Turkey, no study was found concerning domestic violence towards pregnant girls/adolescents who were married.

Domestic violence towards women results in chronic pain, gastrointestinal complaints $(6,13,14)$, depression, low self-esteem, use of alcohol or drugs (14), post-traumatic stress disorder and suicide (7), malnutrition, unplanned pregnancies and pregnancy complications (13) and sexually transmitted diseases such as $\operatorname{HIV} / \operatorname{AIDS}(6,13)$.

This research was therefore conducted in order to determine the extent and types of domestic violence occurring towards pregnant juvenile brides living in the center of Diyarbakir in Turkey.

\section{Methods}

\subsection{Research Design}

This is a sectional, descriptive research study that was carried out in order to determine the situation regarding pregnant juvenile brides' exposure to domestic violence.

\subsection{Participants}

The population of the research consisted of pregnant girls who were between the ages of 10 and 19 between January and July 2016 and who had entered into a juvenile marriage. We planned to reach the entire population without sampling in this study. The research was formed of 79 pregnant juvenile brides of whom 54 were registered in twenty family health centers (ASM's) in the Yenisehir, Kayapinar, Baglar and Sur provinces of Diyarbakir and 25 were not registered. In Turkey, there is an obligation for every pregnant woman to be legally registered at a Family Health Center. However, the same situation does not apply to juvenile marriages. Therefore, snowball sampling was used in these provinces to reach girls who had entered into an unregistered marriage at an early age and had not been through a civil marriage service because of their age. Pregnant child/adolescent brides who were registered at an ASM were called and invited to the ASM. Those who could not come to the ASM were visited at home by appointment. Non-registered married juveniles were contacted via snowball sampling which was implemented with females who had applied to these ASM's for any reason. Research data were acquired by the researchers via the face-to-face interview method using a personal data form prepared using information found in the literature. The form consisted of 26 questions pertaining to basic personal characteristics and experience of violence. Percentages, averages, the Fisher exact and Pearson chi-square tests were used in the analysis of the data.

The most significant factors in choosing these provinces to study were the researchers' belief that these provinces had received more migration from surrounding cities and villages and that such juvenile marriages occurred at earlier ages in these provinces.

\subsection{Data Collection Forms}

A personal data form that was prepared with information found in the literature was used for data collection (15, 16). There were 26 questions in the form; 15 of them were about descriptive aspects (age, educational status, occupation, income status, health insurance, family type, number of marriages, civil marriage, kinship, age of spouse, educational status of spouse, profession, relationship, type of marriage, whether the pregnancy was planned) and 11 of them are about domestic violence (being subjected to violence, the type of violence involved, the person committing the violence, the reaction against violence, the reason for not disclosing the violence).

\subsection{Evaluation of Data}

The data were analyzed using a computer package program (SPSS 16.0). Percentages, averages, the Fisher exact 
and Pearson chi-square tests were used in the analysis of the data. Data were evaluated in 95\% confidence interval.

\subsection{Ethical Aspects of the Study}

Before the study began, the verbal approval of the family health center (TSM), which is connected to the province where the study was conducted, and The ethical permission of the non-invasive clinical research ethical committee of the medical faculty of Dicle University were received (21.01.2016/63). The verbal consent of the participants was obtained. The mutual obligations and the purpose of research were explained to each juvenile before individual interviews. The participants were told they were free to decide whether or not to participate from the first stage of the research and they could end their participation at any point; therefore, the principle of autonomy was followed.

\section{Results}

The findings below were obtained from this research conducted in order to analyze the exposure to violence of pregnant juvenile brides. It was found that all of the pregnant girls/adolescent brides were housewives, $46.8 \%$ of them had completed eight years of education, $89.9 \%$ of them had social insurance, $51.9 \%$ of them were living with an extended family and the income of $94.9 \%$ of them was less than their outgoings. The socio-demographic features of the pregnant child/adolescent brides and their spouses are given in Table 1 . It was found that $26.6 \%$ of the pregnant married children had been subjected to violence. Table 2 shows that $26.6 \%$ of them had been subjected to physical violence, $11.4 \%$ of them to sexual, $27.8 \%$ of them to emotional, $51.9 \%$ of them to verbal and $10.1 \%$ of them to economic violence and that $53.2 \%$ of those carrying out acts of violence were their spouses.

When the findings in Table 3 are analyzed, a statistically significant difference was found between whether pregnant child/adolescent brides were exposed to violence or not with regard to their relationships and whether they had married voluntarily $(\mathrm{P}<0.05)$. In this study, no statistical difference was determined associated with exposure to violence and the spouse's age and situation regarding education, employment and whether the pregnancy was voluntary $(\mathrm{P}<0.05)$.

\section{Discussion}

The average age of the pregnant married juveniles was $17.86 \pm 1.00$. Previous studies reported that the average age of such juveniles was between 16 and 18 (16-18). It can be asserted that the average age of the sampling group included in the study is in accordance with the literature.
It was established that majority of the pregnant children/adolescents who participated in our study were secondary school graduates. In the study conducted by Durmaz (2013) in Diyarbakır on a close date with a similar sampling, it was reported that $40.9 \%$ of the pregnant married juveniles were secondary school graduates. In the studies in the literature, it was determined that many married, pregnant adolescents had completed primary school (19, 20 ). However, in the study conducted by Chang et al. it was established that $60.9 \%$ of the pregnant adolescents were high school graduates (21). With regard to our study, it can be stated that the reason that the pregnant adolescents were secondary school graduates is that eight years of education is compulsory in our country. We are of the opinion that the fact that the pregnant juvenile brides in these studies have different levels of education probably results from regional differences, the differing statuses of women, differing socio-cultural structures and for economic reasons.

According to our study, none of the women were working in an income-generating job. In Durmaz's (2013) doctoral dissertation study with 66 pregnant married juveniles, it was reported that none of them worked (16). In the limited number of research studies conducted in Turkey, it was stated that $62 \%$ - $96 \%$ of pregnant adolescents are not engaged in paid work (18-20). In the study conducted by Thaithae et al. (2011) in Thailand, it was determined that $7.6 \%$ of the pregnant juveniles between the ages of 11 and 15 worked as laborers/agricultural workers, and that $29.4 \%$ of the pregnant adolescents between the ages of 16 and 19 worked as laborers/agricultural workers (20). It is thought that the reason pregnant juveniles are mostly unemployed might result from their young age, high unemployment in the region and a common belief in traditional structures in which women are not able to work outside the home.

Almost all of pregnant juvenile brides who participated in our study stated that their income did not meet their expenses. In another study analyzing the income status of pregnant married children/adolescents, more than half of them stated that their income-expense status was equal (16). In study by Gokce et al. (2007), it was stated that the monthly income of 53.5\% of married pregnant juveniles was between 100 and 199.9 dollars (18). When the literature is reviewed, it is observed that one of the reasons for child pregnancy is poverty. With regard to our study, this high level of poverty might be associated with an increasing rate of unemployment in Turkey and the large number of terror incidents in the region during the period of study.

In our study, it was established that more than half of the married pregnant juveniles lived with their extended family. This situation is similar to the results of other studies (Durmaz, 2013) (16). It can perhaps be assumed the rea- 
Table 1. Distribution of Socio-Demographic Features of Children and Pregnant Bride Spouse

\begin{tabular}{|c|c|c|}
\hline Features & $\mathbf{N}$ & $\%$ \\
\hline The average age & \multicolumn{2}{|c|}{$17.86 \pm 1.00$} \\
\hline \multicolumn{3}{|l|}{ Educational status } \\
\hline Not literate & 7 & 8.9 \\
\hline Literate & 5 & 6.3 \\
\hline Primary school & 21 & 26.6 \\
\hline Secondary school & 37 & 46.8 \\
\hline High school & 9 & 11.4 \\
\hline \multicolumn{3}{|l|}{ Social security } \\
\hline Available & 71 & 89.9 \\
\hline No social security & 8 & 10.1 \\
\hline \multicolumn{3}{|l|}{ Family type } \\
\hline Nuclear family & 38 & 48.1 \\
\hline Extended family & 41 & 51.9 \\
\hline \multicolumn{3}{|l|}{ Income status } \\
\hline Good budget & 4 & 5.1 \\
\hline Poor budget & 75 & 94.9 \\
\hline \multicolumn{3}{|l|}{ Marriage status } \\
\hline Official wedding / religious wedding & 53 & 67.1 \\
\hline Religious wedding & 26 & 32.9 \\
\hline \multicolumn{3}{|l|}{ The partner relationship status } \\
\hline Relative & 29 & 36.7 \\
\hline Not relative & 50 & 63.3 \\
\hline Husband's average age & \multicolumn{2}{|c|}{$24.696 \pm 3.383$} \\
\hline \multicolumn{3}{|l|}{ Husband's educational status } \\
\hline Not literate & 3 & 3.8 \\
\hline Literate & 5 & 6.3 \\
\hline Primary school & 19 & 24.1 \\
\hline Secondary school & 29 & 36.7 \\
\hline High school & 19 & 24.1 \\
\hline University & 4 & 5.0 \\
\hline \multicolumn{3}{|l|}{ Husband's working status } \\
\hline Working & 65 & 82.3 \\
\hline No working & 14 & 17.7 \\
\hline Total & 79 & 100.0 \\
\hline
\end{tabular}

son for the high rate of living with their extended family is that the groom and groom's family can dominate girls more easily and that girls will perform their ascribed responsibilities with less resistance (22).

In our study and other studies in literature, it has been found that married pregnant girls/adolescents have generally entered into a civil marriage $(16,18,19)$. In a study conducted in America, it was reported that $99.7 \%$ of pregnant black adolescents are not married (21). The legal age of marriage in Turkey, the country in which this study was conducted, is 18. However, the legal age limit of marriage can be reduced to 16 with the family's approval and a court decision (4). The different situation found in different countries probably results from the cultural, political and legal differences between them.
Juvenile marriages generally occur between relatives. The reason for this is that parents do not want to give their daughters to strangers, that the social circle is limited (4) and that there is the idea that relatives will take better care of their daughters and more likely to excuse their mistakes in carrying out their duties. In our study, it was determined that there is a substantial degree of kinship between pregnant juvenile brides and their spouses. While the study by Durmaz (2013) supports our findings, the study conducted by Yildizhan et al. (2009) presents a lower rate of kinship between adolescent pregnant women and their spouses. This difference is thought to result from the year the studies were carried out, the regions they were carried out in and the samples used in the studies. Juvenile marriages are higher in almost every region in Turkey, especially in 
Table 2. Distribution of Situation of Pregnant Child Brides Exposed to Violence

\begin{tabular}{|c|c|c|}
\hline Features & $\mathbf{n}$ & $\%$ \\
\hline \multicolumn{3}{|l|}{ Exposure to violance } \\
\hline Yes & 21 & 26.6 \\
\hline No & 58 & 73.4 \\
\hline \multicolumn{3}{|l|}{ Physical violence } \\
\hline Never & 58 & 73.4 \\
\hline 1- 2 times & 6 & 7.6 \\
\hline $3-5$ times & 3 & 3.8 \\
\hline 6 or more times & 12 & 15.2 \\
\hline \multicolumn{3}{|l|}{ Sexual violence } \\
\hline Never & 70 & 88.6 \\
\hline 1-2 times & 5 & 6.4 \\
\hline $3-5$ times & 2 & 2.5 \\
\hline 6 or more times & 2 & 2.5 \\
\hline \multicolumn{3}{|l|}{ Emotional violence } \\
\hline Never & 57 & 72.1 \\
\hline 1-2 times & 9 & 11.4 \\
\hline $3-5$ times & 6 & 7.6 \\
\hline 6 or more times & 7 & 8.9 \\
\hline \multicolumn{3}{|l|}{ Verbal violence } \\
\hline Never & 38 & 48.1 \\
\hline 1-2 times & 16 & 26.3 \\
\hline $3-5$ times & 13 & 16.5 \\
\hline 6 or more times & 12 & 15.1 \\
\hline \multicolumn{3}{|l|}{ Economic violence } \\
\hline Never & 71 & 89.9 \\
\hline 1-2 times & 5 & 6.3 \\
\hline $3-5$ times & 2 & 2.5 \\
\hline 6 or more times & 1 & 1.3 \\
\hline \multicolumn{3}{|l|}{ Who perpetrates violence } \\
\hline No answer & 29 & 36.7 \\
\hline Husband & 42 & 53.2 \\
\hline Other family person & 8 & 10.1 \\
\hline \multicolumn{3}{|l|}{ Violence response } \\
\hline No answer & 45 & 57.0 \\
\hline I remained silent & 29 & 36.7 \\
\hline I'm swearing and shouting at him loudly & 1 & 1.3 \\
\hline I divide the house & 4 & 5.0 \\
\hline \multicolumn{3}{|l|}{ Reason to remain silent } \\
\hline No answer & 48 & 60.8 \\
\hline I do not tell anyone, the event you grow, you go controversy & 23 & 29.2 \\
\hline I cannot turn to her family, no place to go & 3 & 3.8 \\
\hline the division of the family, would be between each spouse & 4 & 6.2 \\
\hline I love my husband & & \\
\hline Total & 79 & 100.0 \\
\hline
\end{tabular}

Southeastern Anatolia and East Anatolia (4). In the western parts of Turkey, the rate of adolescent pregnancy is at 3\%, but it is at a level of $6 \%$ and more in the southeast (10). In conclusion, it can be asserted that the characteristics of the juvenile brides who participated in our study were, with regard to average age, educational status, employment and income status; family type lived in, civil marriage status and kinship to spouse, similar to the results of other stud- ies.

In our study, the pregnant married juveniles stated that they were subjected to violence and that they experienced verbal, physical, emotional, sexual and economic types of violence. The world health organization (2005) reported that the proportion of pregnant women subjected to violence is between 4 and $12 \%$ (23), that one out of four women is subjected to physical or sexual violence by her 


\begin{tabular}{|c|c|c|c|c|c|}
\hline \multirow[t]{2}{*}{ Relationship Status } & \multicolumn{2}{|c|}{ Exposure to Violence } & \multirow[t]{2}{*}{$\mathbf{X}^{2}$} & \multirow[t]{2}{*}{ SD } & \multirow[t]{2}{*}{$\mathbf{P}$} \\
\hline & Yes & No & & & \\
\hline Good & $52.4(11)$ & $93.1(54)$ & & & $0.000^{\mathrm{a}}$ \\
\hline Worse & $47.6(10)$ & $6.9(4)$ & & & \\
\hline \multicolumn{6}{|l|}{ Family type } \\
\hline Nuclear family & $42.9(9)$ & $50.0(29)$ & 0.315 & 1 & $0.575^{\mathrm{b}}$ \\
\hline Extended family & $57.1(12)$ & $50.0(29)$ & & & \\
\hline \multicolumn{6}{|l|}{ Marriage status } \\
\hline Religious wedding & $28.6(6)$ & $34.5(20)$ & 0.244 & 1 & $0.621^{\mathrm{b}}$ \\
\hline Official wedding / religious wedding & $71.4(15)$ & $65.5(38)$ & & & \\
\hline \multicolumn{6}{|l|}{ The partner relationship status } \\
\hline Relative & $24.1(7)$ & $28.0(14)$ & 0.140 & 1 & $0.708^{\mathrm{b}}$ \\
\hline Not relative & $75.9(22)$ & $72.0(36)$ & & & \\
\hline \multicolumn{6}{|l|}{ Income Status } \\
\hline Good budget & $4.8(1)$ & $5.2(3)$ & 1.000 & & $0.714^{\mathrm{a}}$ \\
\hline Poor budget & $95.2(20)$ & $94.8(55)$ & & & \\
\hline \multicolumn{6}{|l|}{ Want marriage } \\
\hline Willingly & $19.0(11)$ & $47.6(10)$ & 6.486 & 1 & $0.011^{\mathrm{b}}$ \\
\hline Unwillingly & $81.0(47)$ & $52.4(11)$ & & & \\
\hline
\end{tabular}

${ }^{\text {a }}$ Fisher's exact test.

${ }^{\mathrm{b}}$ Pearson chi-square.

husband during pregnancy (24), that a pregnant woman's being exposed to violence varies in different countries and is most common in Egypt (32\%), India (28\%), Saudi Arabia (21\%) and Mexico (11\%) (25), that 3\% - $11 \%$ of women in America are subjected to violence during their pregnancy, and that this rate goes up to $38 \%$ in adolescent mothers (26). In another clinical study conducted in Africa (2011), it was reported that women were exposed predominantly to emotional (25\% - 49\%), physical (23\% - 40\%) and sexual (3\% - 27\%) violence during their pregnancies (27). In the study conducted by Giray et al. (2005), it was determined that $20 \%$ of pregnant women were exposed to domestic violence during pregnancy (11). No study could be found in the literature concerning domestic violence towards pregnant married juveniles. Domestic violence studies are generally conducted with adult women. In foreign studies, it is often stated that pregnant adolescents conceive through extramarital intercourse. This study was carried out with girls who had married in a civil and/or religious marriage ceremony and whose marriage had been approved by their families and immediate social circles. Furthermore, domestic violence in juvenile marriages is mostly studied retrospectively. Since our study was performed with married girls/adolescents who were pregnant at the time, no study could be found in the literature with which to make a headto-head comparison. However, it can be asserted as a result of our study that the rates of domestic violence and the types of violence to which pregnant married juveniles are subjected have similarities with the rates of domestic violence and types of violence which women in the adult population and other adolescent girls experience.

In this study, it was determined that the educational status, income status, family type, civil marriage status and having a planned pregnancy do not influence the exposure to violence but whether the marital relationship is perceived by pregnant girls/adolescents as good or bad does affect whether violence is experienced. In our study, the age, educational status, profession, economic status, family type, and kinship with the spouse of pregnant child bride did not affect the presence of domestic violence. In the study conducted by Giray et al. (2005), the age of the pregnant woman and her spouse, having a job, economic status, family type, kinship between spouses, type of marriage, the number of children and years of marriage did not affect the presence of domestic violence. On the other hand, women who experience physical violence at other times during their marriage are more likely to be exposed to violence during their pregnancy than those who do not (11). From this study and the study conducted by Giray et al. it is possible to assert that whether the relationship is perceived by spouses as good or bad increases or reduces domestic violence. In Guler's study (2010), there was a statistically significant difference found between whether a pregnant woman was subjected to physical, emotional, sexual 
and economic violence with regard to her spouse's educational status, employment status, economic status and whether the pregnancy was planned (28). In a study by Giray et al. the fact that a pregnancy had been planned and that marriage had been entered into voluntarily did not affect exposure to violence (11). In Guler's study (2010), there was a difference found between whether or not the pregnancy had been planned and whether or not the pregnant woman was subjected to violence (28). In our study, having married voluntarily reduced the degree of exposure to violence. It is possible to state that this finding is partially consonant with the literature.

Nurses providing healthcare services belong to the occupational group that works with individuals in society in the most face-to-face way. Within the framework of their traditional and contemporary roles, nurses occupy a position that allows them to educate individuals and society about juvenile marriages and adolescent pregnancies and the sexually-transmitted infections and reproductive health risks that might arise during pregnancy, birth, the post-natal period and throughout life. Therefore, any training which raises awareness of these could well be instructive in preventing juvenile marriages and pregnancies and in managing current pregnancies. To this end, nurses should provide more comprehensive healthcare to women, and guide and encourage them through home visits to use the services available. Measures taken at an early stage might well help a woman to live a healthier life in future periods (29).

\subsection{Limitations of the Research}

There are some limitations to this study. Firstly, while it is possible to receive written or verbal consent of women who are 18 or over, for females under 18 parental approval should have been granted. The intention was to receive the approval of the parents/legal guardians of the girls/adolescents involved but these approvals were only received verbally since the families said that it was necessary to receive the permission of their daughters' spouses because they were married and some of the participants stated that they did not want to engage with their spouses.

Secondly, people migrated from two provinces (Sur and Baglar) due to terrorist attacks during the period in which the study was being conducted and it had been planned to include these provinces in the research sample. Therefore, it was not possible to attain the size of sample that had been planned.

Thirdly, the fact that this was a study about violence caused some of the juveniles or their accompanying family member to refuse to participate in the study. This prevented the size of the sampling which had been planned from being attained.
Fourthly, although the researcher wanted to perform interviews personally, family members who were accompanying some of the juveniles were absolutely opposed to this. It is thought that this situation might have affected the study's results.

The fifth restriction is that since the participants had married at an early age through a religious ceremony instead of civil marriage, this situation caused them to appear 'unmarried' in official records. Since this prevented us from determining the exact number to be used in the sample, only an approximate sampling was taken.

The strongest aspect of this study is that it is the only study have been conducted in an attempt to determine the degree of domestic violence towards child or adolescent brides who were currently pregnant, because, as far as we could find in the literature, all of the previous studies were retrospective studies.

\subsection{Conclusion}

Domestic violence towards pregnant married juveniles remains at a considerable level. Furthermore, it was determined that there was no significant relation between domestic violence towards pregnant married girls/adolescents and their essential personal characteristics but that such violence is related to whether the marriage was planned and whether the status of the relationship is perceived to be good or bad. Moreover, it was seen that these results are similar to results regarding domestic violence towards adult women.

If a woman is determined to be subject to domestic violence as a result of her application to the health institution, duties of health personnel include documenting the woman's abuse history, performing diagnostic, therapeutic, and follow-up activities, performing risk assessment, developing a security plan, informing the victim, referring the victim to protection and assistance services, recording the case, and notifying authorities. In this process, health personnel ensure that the victim fills the domestic violence form, notify the hospital police, perform reporting and risk assessment activities, and refer the victim to other health institutions if necessary. It is necessary to prevent underage marriages and raise awareness in the society regarding domestic violence in underage marriages. It is recommended that socio-centric projects are conducted, mostly on prevention of underage marriages, to protect the rights of adolescents (both girls and boys), establish equality in terms of social status, meet their health-related and educational needs and, most importantly, protect them against violence. 


\section{Acknowledgments}

The authors present their thanks to all participating pregnant married juveniles in current study.

\section{Footnote}

Funding/Support: The authors received no financial support for the research, authorship, and/or publication of this article.

\section{References}

1. Ending Child Marriage a Guide for Global Policy Action. . International planned parenthood federation (IPPF) and the forum on marriage and the rights of women and girls 2006. [cited 08/08]. Available from: http://www.unfpa.org/upload/lib_pub_file/62_filenema_ endchildmarriage.pdf.

2. United Nations Children's Fund ECM(. Progress and prospects. UNICEF; .

3. Chae S. Timing of orphanhood, early sexual debut, and early marriage in four sub-Saharan African countries. Stud Fam Plann. 2013;44(2):12346. doi: 10.1111/j.1728-4465.2013.00349.x. [PubMed: 23719999].

4. Turkiye Buyuk Millet Meclisi. . Kadin erkek firsat esitligi komisyonu: erken yasta evlilikler hakkinda inceleme yapilmasina dair rapor. ; .

5. Stockl H, Devries K, Rotstein A, Abrahams N, Campbell J, Watts C, et al. The global prevalence of intimate partner homicide: a systematic review. Lancet. 2013;382(9895):859-65. doi: 10.1016/S0140-6736(13)610302. [PubMed: 23791474].

6. Nasrullah M, Zakar R, Zakar MZ. Child marriage and its associations with controlling behaviors and spousal violence against adolescent and young women in Pakistan. JAdolesc Health. 2014;55(6):804-9. doi: 10.1016/j.jadohealth.2014.06.013. [PubMed: 25123525].

7. Godha D, Hotchkiss D, Gage A. The influence of child marriage on fertility fertility-control and maternal health care utilization: a multicountry study from South Asia. 373. Lancet; 2009. pp. 1883-9.

8. Gage AJ. Association of child marriage with suicidal thoughts and attempts among adolescent girls in Ethiopia. J Adolesc Health. 2013;52(5):654-6. doi: 10.1016/j.jadohealth.2012.12.007. [PubMed: 23433537].

9. World Health Organization. . Intimate partner violence during pregnancy 2011. [cited 20 december]. Available from: http://apps.who.int/ iris/bitstream/10665/70764/1/WHO_RHR_11.35_eng.pdf.

10. Adolescent fertility and motherhood. . Turkey Demographic and Health Survey, Ankara, Turkey. 2013 :72-3.

11. Giray H, Keskinoglu P., Sonmez Y. . Domestic violence and associations during pregnancy. STED. 2005;14(10):217-20.

12. Ayranci U, Gunay Y. , Unluoglu I. . Spouse violence during pregnancy: A research among women attending to primary health care. Anatolian J Psychiat. 2002;3(2):75-87.
13. Le MTH, Tran TD, Nguyen HT, Fisher J. Early marriage and intimate partner violence among adölescents and young adults in Viet Nam. Jinterpers Violence. 2013;20:1-22.

14. Devries K, Watts C, Yoshihama M, Kiss L, Schraiber LB, Deyessa N, et al. Violence against women is strongly associated with suicide attempts: evidence from the WHO multi-country study on women's health and domestic violence against women. Soc Sci Med. 2011;73(1):79-86. doi 10.1016/j.socscimed.2011.05.006. [PubMed: 21676510].

15. Gumus F, Elmaci N, Ertem M. Domestic violence against women: Sample of a different ethnic group. JBCS. 2014;3(2):23-33.

16. Durmaz BG, Guducu TF. Self-esteem and self-care abilities in preg nant adolescents: a pretest-posttest quasi-experimental study. JCS. 2016;9(3):876-93

17. Yildizhan R., Kolusari A. , Edirne T. . Analysis of adolescent pregnancy at the district of Van. Van Tip Dergisi. 2009;16(4):124-7.

18. Gokce B, Ozsahin A, Zencir M. Determinants of adolescent preg nancy in an urban area in Turkey: a population-based case-control study. J Biosoc Sci. 2007;39(2):301-11. doi: 10.1017/S0021932006001763. [PubMed: 17107636].

19. Ezegwui HU, Ikeako LC, Ogbuefi F. Obstetric outcome of teenage preg nancies at a tertiary hospital in Enugu, Nigeria. Niger J Clin Pract 2012;15(2):147-50. doi:10.4103/1119-3077.97289. [PubMed: 22718161].

20. Thaithae $S$, Thato R. Obstetric and perinatal outcomes of teenage pregnancies in Thailand. J Pediatr Adolesc Gynecol. 2011;24(6):342-6. doi:10.1016/j.jpag.2011.02.009. [PubMed: 22099731].

21. Chang SC, O'Brien KO, Nathanson MS. Characteristics and risk factors for adverse birth outcomes in pregnant black adolescents. J Pediatr. 2003;143(2):250-7.

22. Hervish A, Feldman-Jacobs H. Qui parle en mon nom? Mettre fin au marıge des enfants. ; 2011

23. García-Moreno C, Jansen HA, Ellsberg M, Heise L, Watts C. WHO multicountry study on women's health and domestic violence against women: initial results on prevalence, health outcomes and women's responses. World Health Organization. 2005.

24. Golding JM, Cooper ML, George LK. Sexual assault history and health perceptions: seven general population studies. Health Psychol. 1997;16(5):417-25. [PubMed: 9302538].

25. Campbell J, Garcia-Moreno C, Sharps P. Abuse during pregnancy in industrialized and developing countries. Violence Against Wom. 2004;10(7):770-89.

26. Curry MA, Perrin N, Wall E. Effects of abuse on maternal complications and birth weight in adult and adolescent women. Obstetric Gynecol. 1998;92:530-4.

27. Shamu S, Abrahams N, Temmerman M, Musekiwa A, Zarowsky C. A systematic review of African studies on intimate partner violence against pregnant women: prevalence and risk factors. PLoS One 2011;6(3):17591. doi: 10.1371/journal.pone.0017591. [PubMed: 21408120].

28. Guler N. Physical, emotional, sexual, and economic violence by spouse during pregnancy and associated factors. Deuhyo. 2010;3(2):72-7.

29. Yakit E. , Coskun A. M. . The truth of child marriage in a social context responsibilities of the nurse and midwife. J Nurs Educ. 2014;11(3):3-11. 